\title{
Factor Analysis of Social Aspects of Consumer Choice of Organic Products
}

\author{
Lezhebokov A.A.* \\ Department of Sociology \\ North-Caucasus Federal University \\ Stavropol, Russia \\ lezhebokov.a@inbox.ru
}

Ivashova V.A.

Consumer Expectations Monitoring Department

Stavropol State Agrarian University

Stavropol, Russia

vivashov@mail.ru

\author{
Nesmeyanov E.E. \\ Department of Philosophy and World Religions \\ Don State Technical University \\ Rostov-on-don, Russia \\ nesmeyanoff.e@yandex.ru
}

\author{
Narozhnaya G. A. \\ Department of Regional Management \\ Moscow Technological University (Stavropol Branch), \\ Stavropol, Russia \\ Strelec_ribi@mail.ru
}

\author{
Ponomarenko M.V. \\ Department of Economic Theory and Economics of Agriculture \\ Stavropol State Agrarian University \\ Stavropol, Russia \\ marina307@inbox.ru
}

\begin{abstract}
The article presents the results of research of social aspects of consumer choice of organic products. The issues of safe and proper nutrition are gaining importance in all regions of the world. The territories of the North Caucasus of Russia due to their natural and climatic peculiarities are represented by well-developed agrarian sector, favorable environmental conditions and have opportunities to expand production of organic food. Growing demand for organic food updates the research search and justification of social aspects of consumer choice of organic products. Modeling of social aspects of consumer choice of organic products was conducted on the example of a survey of the population of the Stavropol Territory. The research method was an anonymous questionnaire survey and factor analysis of indicators of organic products selection and purchasing decision making by consumers with different education levels. A total of 417 people who live in the Stavropol Territory took part in the survey. The S.P.S.S. Statistics package S.P.S.S. Statistics (version 21) helped to build the factor model. The modeling was based on the evaluation of 7 indicators to assess the significance of specific characteristics of organic products, which eventually led to a favorable decision to buy. As an independent variable, two categories of survey participants, which differ by the level of education, were identified: "higher" respondents who have a level of higher education and "secondary" - respondents who have a level of general education. Differences in the factor model of these categories of residents determine strategic approaches to promoting organic food on the market in southern Russia. Correct understanding of consumer expectations and compliance with them expands the opportunities for organic food production and consumption.
\end{abstract}

Keywords - organic food; consumer choice; factor analysis.

\section{INTRODUCTION AND LITERATURE REVIEW}

Food safety issues are becoming more acute against the background of unfavorable ecological situation in some regions. Improper use of chemical preparations for pest and disease control, application of fertilizers, chemical production wastes, etc. harm the quality characteristics of food for humans and animals. Thus the authors Afonne O.J., Ifediba E.C. in their article note that growing crops in contaminated areas can seriously affect the quality and safety of food. The consumption of such products represents a potential risk to global food security and healthy living [1]. So there is a need for proven organic foods, the demand for which is increasing worldwide. The research community brings up the issue of people's motivation to buy organic food and consumer behavior. Authors Feil A.A., Cyrne C.C.D.S., Sindelar F.C.W., Barden J.E., Dalmoro M. [2] the article analyzes the relationship between socio-economic and demographic characteristics of consumers of organic food products and their motivations, perception and attitude to food safety. It is possible to formulate the features of consumer profiles determining sustainable forms of consumer behavior.

As research practice shows, not all organic product offerings are positively responded to by consumers. Authors Jorge E., Lopez-Valeiras E., Gonzalez-Sanchez M.B. [3] in their study show that a significant proportion of consumers, with a generally positive attitude towards organic products, do not accept organic wine. It is because of their negative attitude towards alcohol consumption in any quality.

The authors of the article "Consumers' trust in food safety indicators and cues: The case of Vietnam" [4] Le A.T., Nguyen M.T., Vu H.T.T., Nguyen Thi T.T. analyzed the impact of 
labeling, place of production, the reputation of the store, government certificate, information from friends, price and appearance of the product on consumer choice. As a result of the research, the most significant argument for the decision is the qualitative characteristic of the product composition and the presence of state certification, confirming this level of quality.

Consumers attribute the quality of organic products to their production conditions. Consumers demonstrate a willingness to pay not only for the composition of their components but also for environmentally friendly and non-industrial production conditions. For example, researchers Stampa E., Schipmann-Schwarze C., Hamm U. speak about the perception and preferences of consumers of animal products grown on pastures [5]. In this case, consumers are willing to pay not only for organic properties but also for food production conditions.

Labeling plays an essential role in consumers' choice of organic food. In a study by Aitken R., Watkins L., Williams J., Kean A. [6] found that it is labeling that primarily affects the behavioral intentions of consumers. By improving labeling systems, it is possible to offer consumers essential and relevant information about organic food.

Some studies have proposed the most typical consumer profile for organic products and the factors influencing consumer choice [7, 9-12] and have emphasized the social and environmental importance of natural food preferences. The authors of the article "Individuals' personality and consumption of organic food" offer an essential supplement to the discussion about the prospects of organic food consumption [13]. It concerns the analysis of the relationship between the individual's personality and the choice of organic food. Among consumers, the most receptive to this choice of personality are those open to new experiences. Stakeholders can take this into account when planning strategies and methods to increase organic food sales.

An important socio-economic aspect in the analysis of consumer preferences is the attitude of the younger generation to organic food. In a study by Melović B., Dabić M., Rogić S., Đurišić V., Prorok V., based on a factor analysisthe vast majority of young consumers consider organic products to be healthy and natural. However, their higher price is a significant barrier that prevents them from making a purchase decision [8].

Luomala H., Puska P., Lähdesmäki M., Siltaoja M., Kurki S. proposedsocial aspects of organic food consumption [14]. The studyestablished the relationship between the use of organic food and prosocial consumer status signalling. Thus, the choice and purchase of organic food is an example of prosocial personal behavior. The consumer demonstrates a willingness to benefit other people or society as a whole. Psychological - positive emotions of the consumer complement the social aspects of organic food consumption. [15-18].

Thus, a brief review of current publications characterizing the consumption of organic food shows the relevance, importance and diversity of the topic for different regions of the world. At the same time, purely practical issues of composition and labeling of these products go into a discussion along with socio-psychological and environmental aspects of the distinctive importance of organic food consumption.

\section{MATERIAL AND METHODS}

Modeling of social aspects of consumer choice of organic products was conducted on the example of a survey of the population of the Stavropol Territory. The research method was an anonymous questionnaire survey and factor analysis of indicators of organic products selection and purchasing decision making by consumers with different education levels. A total of 417 people who live in the Stavropol Territory took part in the survey. The S.P.S.S. Statistics package S.P.S.S. Statistics (version 21) helped to build the factor model. The modeling was based on the evaluation of 7 indicators to assess the significance of specific characteristics of organic products, which eventually led to a favorable decision to buy. As an independent variable, two categories of survey participants, which differ by the level of education, were identified: "higher" - respondents who have a level of higher education and "secondary" - respondents who have a level of general education. Differences in the factor model of these categories of residents determine strategic approaches to promoting organic food on the market in southern Russia.

\section{RESULTS}

S.P.S.S. Statistics (version 21) conducted a factor analysis of the research database after it was possible to group the listed indicators of the selection of organic products and the decision to buy by consumers with different levels of education. And to identify more significant groups of factors separately for respondents with higher and secondary education.

The full explained dispersion is $79.7 \%$, and four components determine it.

TABLE I. FULL EXPLAINED DISPERSION FOR THE CATEGORY OF CONSUMERS WITH HIGHER EDUCATION

\begin{tabular}{|c|c|c|c|c|c|c|c|c|c|}
\hline \multirow[t]{2}{*}{ component } & \multicolumn{3}{|c|}{ Initial eigenvalues } & \multicolumn{3}{|c|}{ Sums of extraction load squares } & \multicolumn{3}{|c|}{ Sums of rotation load squares } \\
\hline & Total & \% Dispersion & Cumulative \% & Total & \% Dispersion & Cumulative \% & Total & \% Dispersion & Cumulative \% \\
\hline 1 & 1,807 & 25,816 & 25,816 & 1,807 & 25,816 & 25,816 & 1,503 & 21,474 & 21,474 \\
\hline 2 & 1,375 & 19,636 & 45,452 & 1,375 & 19,636 & 45,452 & 1,438 & 20,539 & 42,014 \\
\hline 3 & 1,285 & 18,350 & 63,802 & 1,285 & 18,350 & 63,802 & 1,372 & 19,603 & 61,616 \\
\hline 4 & 1,111 & 15,866 & 79,668 & 1,111 & 15,866 & 79,668 & 1,264 & 18,052 & 79,668 \\
\hline 5 & 0,912 & 13,022 & 92,690 & & & & & & \\
\hline 6 & 0,512 & 7,310 & 100,000 & & & & & & \\
\hline 7 & $1,729 \mathrm{E}-16$ & $2,470 \mathrm{E}-15$ & 100,000 & & & & & & \\
\hline
\end{tabular}


TABLE II. MATRIX OF ROTATED COMPONENTS FOR THE CATEGORY OF CONSUMERS WITH HIGHER EDUCATION

\begin{tabular}{|l|l|c|c|c|}
\hline \multicolumn{1}{|c|}{ Rotated Component Matrix } & \multicolumn{4}{c|}{ Component } \\
& $\mathbf{1}$ & $\mathbf{2}$ & $\mathbf{3}$ & \multicolumn{1}{|c|}{} \\
\hline 1. Price & 0.435 & -0.165 & $\mathbf{0 . 7 0 4}$ & 0.323 \\
\hline $\begin{array}{l}\text { 2. Availability of products in familiar } \\
\text { places of sale }\end{array}$ & -0.002 & 0.030 & 0.110 & $\mathbf{- 0 . 9 5 3}$ \\
\hline $\begin{array}{l}\text { 3. Better appearance of organic products } \\
\text { 4. Strict rules in the production of } \\
\text { organic products }\end{array}$ & 0.004 & $-\mathbf{0 . 9 3 3}$ & 0.106 & 0.083 \\
$\begin{array}{l}\text { 5. 5. Confirmation of quality standards } \\
\text { for organic products }\end{array}$ & -0.502 & -0.021 & $\mathbf{- 0 . 9 1 3}$ & 0.03 \\
\hline $\begin{array}{l}\text { 6. Local production of organic products } \\
\text { 7. Environmentally friendly packaging. }\end{array}$ & $\mathbf{- 0 . 6 8 3}$ & 0.766 & 0.091 & 0.390 \\
\hline
\end{tabular}

The listed seven organic food attributes for the category of consumers with higher education as a result of factor analysis performed by Rotation Method: Varimax with Kaiser Normalization (Rotation converted into nine iterations) were grouped into four factors.

In terms of the content of the grouped characteristics, the set ofvariables determines the first factor: a negative value of local production of organic products (factor load factor $\mathbf{0 . 6 8 3}$ ); environmentally friendly packaging (factor load factor 0.766). So imported products in environmentally friendly packaging interpret the first factor

The set ofvariables determines the second factor: a negative value of the best appearance of organic products $(-\mathbf{0 . 9 3 3})$; confirmation of organic products quality standards (0.528). So an optional attractive type of products interprets the second factor, but with mandatory approval of quality standards of organic products.

The set ofvariables determines the third factor: the price of organic food $(\mathbf{0 . 7 0 4})$; a negative value of the attribute strict rules in the production of organic products $(-\mathbf{0 . 9 1 3})$. Therefore matching the price and strict standards of production interprets the third factor

The set of variables determine the fourth factor: the negative value of the attribute - the presence of products in the usual places of sales $(\mathbf{- 0 . 9 5 3 )}$. Thus, the presence of select areas of the sale of organic products interprets the fourth factor.

TABLE III. CONVERSION MATRIX COMPONENT FOR THE CATEGORY OF

\begin{tabular}{|l|l|l|l|l|}
\hline \multicolumn{1}{c|}{ CONSUMERS WITH HIGHER EDUCATION } \\
\hline 1 & \multicolumn{1}{c|}{$\mathbf{1}$} & \multicolumn{1}{|c|}{$\mathbf{2}$} & \multicolumn{1}{c|}{$\mathbf{3}$} & \multicolumn{1}{|c|}{$\mathbf{4}$} \\
\hline 2 & 0.693 & -0.385 & 0.587 & -0.166 \\
\hline 3 & 0.331 & 0.921 & 0.196 & -0.061 \\
\hline 4 & 0.409 & -0.035 & -0.259 & 0.874 \\
\hline
\end{tabular}

Table 4 shows the full explained dispersion for the category of respondents with secondary education. The complete explained dispersion is $75.6 \%$, and three components define it.

TABLE IV. FULL EXPLAINED DISPERSION FOR THE CATEGORY OF CONSUMERS WITH SECONDARY EDUCATION

\begin{tabular}{|c|c|c|c|c|c|c|c|c|c|}
\hline \multirow[b]{2}{*}{ component } & \multicolumn{3}{|c|}{ Initial eigenvalues } & \multicolumn{3}{|c|}{ Sums of extraction load squares } & \multicolumn{3}{|c|}{ Sums of rotation load squares } \\
\hline & Total & \% Dispersion & Cumulative \% & Total & \% Dispersion & Cumulative \% & Total & \% Dispersion & Cumulative \% \\
\hline 1 & 2,156 & 30,793 & 30,793 & 2,156 & 30,793 & 30,793 & 1,843 & 26,334 & 26,334 \\
\hline 2 & 1,725 & 24,645 & 55,439 & 1,725 & 24,645 & 55,439 & 1,826 & 26,091 & 52,424 \\
\hline 3 & 1,410 & 20,138 & 75,577 & 1,410 & 20,138 & 75,577 & 1,621 & 23,153 & 75,577 \\
\hline 4 & 0,940 & 13,426 & 89,003 & & & & & & \\
\hline 5 & 0,570 & 8,150 & 97,153 & & & & & & \\
\hline 6 & 0,199 & 2,847 & 100,000 & & & & & & \\
\hline 7 & $-1,672 \mathrm{E}-16$ & $-2,388 \mathrm{E}-15$ & 100,000 & & & & & & \\
\hline
\end{tabular}

TABLE V. ROTATED COMPONENT MATRIX FOR CONSUMERS WITH SECONDARY EDUCATION

\begin{tabular}{|l|c|c|c|c|}
\multicolumn{1}{|c}{ Rotated Component Matrix } & \multicolumn{5}{c|}{ Component } \\
\hline & $\mathbf{1}$ & $\mathbf{2}$ & $\mathbf{3}$ & $\mathbf{4}$ \\
\hline 1. Price & -0.699 & 0.046 & -0.331 & -0.699 \\
\hline $\begin{array}{l}\text { 2. Availability of products in familiar } \\
\text { places of sale }\end{array}$ & -0.751 & 0.064 & 0.246 & -0.751 \\
$\begin{array}{l}\text { 3. Better appearance of organic products } \\
\text { 4. Strict rules in the production of organic } \\
\text { products }\end{array}$ & 0.130 & -0.157 & 0.944 & 0.130 \\
\hline $\begin{array}{l}\text { 5. Confirmation of quality standards for } \\
\text { organic products }\end{array}$ & 0.479 & 0.917 & -0.006 & 0.122 \\
\hline 6. Local production of organic products & 0.041 & -0.944 & 0.093 & 0.041 \\
\hline 7. Environmentally friendly packaging. & 0.727 & 0.240 & -0.111 & 0.727 \\
\hline
\end{tabular}

The listed seven attributes of organic food for the category of consumers with secondary education as a result of factor analysis performed by Rotation Method: Varimax with Kaiser Normalization (Rotation converted into five iterations) were grouped into three factors. Table 5 shows the data.

According to the content of the grouped characteristics, a set of variables determines the first factor: a negative value of the price of organic products (factor load factor - $\mathbf{0 . 6 9 9}$ ); a negative value of the attribute - the presence of products in the usual places of sale (factor load factor - $\mathbf{0 . 7 5 1}$ ); environmentally friendly packaging (factor load factor $\mathbf{0 . 7 2 7}$ ). Thus, the first factor can be interpreted as the sale of organic products in select locations at an affordable price and environmentally friendly packaging. 
The set of variables determines the second factor: strict rules in the production of organic products (0.917); a negative value of the attribute - local production of organic products (0.944). Thus, the second factor can be interpreted as the observance of strict rules in the production of organic products produced in other territories.

The set of variables determines the third factor: the better appearance of organic products $(\mathbf{0 . 9 4 4 )}$; a negative value of the attribute - confirmation of organic products quality standards (-0.734). Therefore the third factor can be interpreted as a prevalence of external quality characteristics of organic products, defined visually, not a documentary.

TABLE VI. CONVERSION MATRIX COMPONENT FOR THE CATEGORY OF

\begin{tabular}{|c|c|c|c|c|}
\hline \multicolumn{5}{|c|}{ CONSUMERS WITH SECONDARY EDUCATION } \\
\hline Component & 1 & 2 & $\mathbf{3}$ & 4 \\
\hline 1 & 0.639 & 0.556 & -0.531 & 0.639 \\
\hline 2 & -0.639 & 0.768 & 0.035 & -0.639 \\
\hline 3 & 0.427 & 0.318 & 0.846 & 0.427 \\
\hline
\end{tabular}

\section{CONCLUSION}

Therefore, based on the conducted factor analysis, it is possible to concludethe essential difference of consumer expectations depending on respondents' education level.

Consumer choice of respondents with higher education forms under the influence of the following aspects:

- brought products in environmentally friendly packaging;

- not necessarily attractive type of products, but with obligatory confirmation of quality standards of organic products;

- conformity of price and strict rules of production;

- availability of special places for selling organic products.

Consumer choice of respondents with higher education forms under the influence of the following aspects:

- sale of organic products in special places at an affordable price and environmentally friendly packaging.

- compliance with strict rules in the production of organic products produced in other territories.

- prevalence of external quality characteristics of organic products defined visually rather than in documentary terms.

Good understanding and compliance with consumer expectations enhance the ability to produce and consume organic food.

\section{Acknowledgments}

The research was carried out with the financial support of the Russian Foundation for Basic Research under scientific project No. 20-011-00260 "Prospects of Socio-cultural Development of the Karachay-Cherkessia Republic" .

\section{References}

[1] O.J. Afonne, E.C. Ifediba, "Heavy metals risks in plant foods - need to step up precautionary measures", Current Opinion in Toxicol., no. 22, pp. $1-6,2020$

[2] A.A. Feil, C.C.D.S. Cyrne, F.C.W. Sindelar, J.E. Barden, M. Dalmoro, "Profiles of sustainable food consumption: Consumer behavior toward organic food in southern region of Brazil", J. of Cleaner Product., p. 258, 2020

[3] E. Jorge, E. Lopez-Valeiras, M.B. Gonzalez-Sanchez, "The role of attitudes and tolerance of ambiguity in explaining consumers' willingness to pay for organic wine", J. of Cleaner Product., p. 257, 2020

[4] A.T. Le, M.T. Nguyen, H.T.T. Vu, T.T. Nguyen Thi, "Consumers' trust in food safety indicators and cues: The case of Vietnam", Food Control, p. 112, 2020,

[5] E. Stampa, C.Schipmann-Schwarze, U. Hamm, "Consumer perceptions, preferences, and behavior regarding pasture-raised livestock products: A review", Food Quality and Preference, p. 82, 2020.

[6] R. Aitken, L. Watkins, J. Williams, A. Kean, "The positive role of labelling on consumers' perceived behavioural control and intention to purchase organic food”, J. of Cleaner Product.,p. 255, 2020.

[7] R. Rodríguez-Bermúdez, M. Miranda, I. Orjales, W. Al-Soufi, M. López-Alonso, "Consumers' perception of and attitudes towards organic food in Galicia (Northern Spain)”, Int. J. of Consumer Stud., vol. 44, no. 3, pp. 206-219, 2020.

[8] B. Melović, M Dabić, S. Rogić, V. Đurišić, V. Prorok, "Food for thought: Identifying the influential factors that affect consumption of organic produce in today's youth", British Food J., vol. 122, no. 4, pp. 1130-1155, 2020.

[9] E.A.M. Watanabe, S. Alfinito, I.C.G. Curvelo, K.M. Hamza, "Perceived value, trust and purchase intention of organic food: a study with Brazilian consumers", British Food J., vol. 122, no. 4, pp. 1070-1184, 2020

[10] I. Kamenidou, A. Stavrianea, E.-Z. Bara, "Generational differences toward organic food behavior: Insights from five generational cohorts", Sustainability (Switzerland), vol. 12, no. 6, p. 2299, 2020.

[11] S. Mohanty, "An assessment of theory of reasoned action towards organic food in india", Int. J. of Sci. and Technol. Res., vol. 9, no. 3, pp. 7233-7235, 2020 .

[12] K. Boobalan, G.S. Nachimuthu, "Organic consumerism: A comparison between India and the U.S.A", J. of Retail. and Consumer Services, p. 53,2020

[13] G.W. Gustavsen, A.W. Hegnes, "Individuals' personality and consumption of organic food", J. of Cleaner Product., p. 245, 2020

[14] H. Luomala, P. Puska, M. Lähdesmäki, M. Siltaoja, S. Kurki,“Get some respect - buy organic foods! When everyday consumer choices serve as prosocial status signaling", Appetitep, no. 145, 2020.

[15] D. Ismael, A. Ploeger, "Consumers' emotion attitudes towards organic and conventional food: A comparison study of emotional profiling and self-reported method", Foods, vol. 9, no. 1, p. 79, 2020.

[16] V.N. Goncharov, E.E. Nesmeyanov, O.U. Kolosova, V.V. Arutyunyan, V.A. Ivashova, "Analysis of the modern science and technology in the context of the concept of CDIO", J. of Phys.: Conf. Ser. The conf. proc. HIRM-2019. AeroSpace school, IT Lab, p. 012135, 2019.

[17] V.N. Goncharov, A.M. Erokhin, V.A. Ivashova, O.U. Kolosova, L.A. Tronina, O.N. Kamalova, "Social responsibility and professional competence of safegueard specialists for the quality and safety of food products", IOP Conf. Ser. Earth and Environmental Sci., p. 012124 , 2020. Voronezh State Agrarian University named after Emperor Peter the Great.

[18] K.V. Vodenko, O.S. Ivanchenko, L.A. Shvachkina, E.L. Shilkina, V.I. Rodionova, "Formation of the national management system in the field of personnel training for modern innovative economy", Int. J. of Appl. Busin. and Econ. Res., vol. 15, no. 11, pp. 197-205, 2017. 